\title{
EDUCAÇÃO AMBIENTAL NO ASSENTAMENTO FILHOS DE SEPÉ: CONTRIBUIÇÕES DE UMA EXPERIÊNCIA ${ }^{1,2}$
}

Grupo PET-Geografia ${ }^{3}$

\section{Resumo}

Este projeto tem como objetivo o desenvolvimento de atividades ligadas a educação em um assentamento da reforma agrária. A partir do desenvolvimento de um diagnóstico sócio-cultural de percepção ambiental no local, traçamos o objetivo fundamental deste projeto seguinte, que consiste na ampliação dos conceitos de ambiente, natureza, ecologia e educação ambiental das crianças, jovens e adultos do assentamento, com especial atenção na superação da visão antropocêntrica e individualista predominante na sociedade ocidental. Ele está estruturado em três pilares fundamentais: Dimensão Histórico-Cultural, Dimensão SócioEconômica e Dimensão Biogeográfica. Estas dimensões nos possibilitarão um desenvolvimento mais abrangente das experiências vividas, da relação com o meio ambiente, da relação com os movimentos do campo, das dificuldades enfrentadas, etc.

Para atingirmos os nossos objetivos, utilizaremos os mais diferentes recursos pedagógicos, desde os mais tradicionais, até a utilização do teatro, da música, dos mapas mentais, etc.

O descaso que existe em relação à educação por parte dos governantes em nosso país, somado com a necessidade de incluir aqueles que estão à margem de nossa sociedade, motiva o PET (Programa Educação Tutorial) Geografia ao desenvolvimento desta atividade tão instigante que é a educação ambiental.

Palavras-Chave: Educação Ambiental, Assentamento, Dimensão Histórico-Cultural, Dimensão Sócio-Econômica, Dimensão Biogeográfica.

\footnotetext{
${ }^{1}$ Relatório de Pesquisa

${ }^{2}$ Artigo Publicado XVI SIC

${ }^{3}$ Ana Stumpf Mitchell; Fábio Guadagnin; Felipe Silveira de Souza; Fernando Mousquer; Gustavo Luís Ferri Furini; Judeci da Silva; Márcia Milene Müller; Neudy Alexandro Demichei; Tiago Oliveira Nicoloso.; Prof ${ }^{\mathrm{a}}$. Dr ${ }^{\mathrm{a}}$. Rosa Maria Vieira Medeiros.
} 


\section{Introdução}

É pertinente ao Ministério da Educação (MEC), segundo a legislação vigente, tornar a Educação Ambiental parte do itinerário de todos os alunos e educadores, tornando-a parte essencial na educação de todos os cidadãos. A Educação Ambiental, no entanto, por razões diversas, ou não está ao alcance das instituições tradicionais de ensino, ou está inserida de forma insatisfatória.

No momento da realização do diagnóstico, o assentamento apresentava ainda grande parte das residências em condições precárias, algumas delas construídas de lonas. As poucas casas de alvenaria são herança das antigas instalações da Fazenda Santa Fé, ou no caso específico do setor D, resultantes do dinheiro adquirido a partir da venda da mata de eucaliptos existente no momento de instalação do assentamento, naquele local. Esta situação ocorre em virtude de que grande parte dos assentados aguarda o recebimento da verba destinada à moradia.

Além do problema da moradia, existem dificuldades quanto ao fornecimento de água e de energia elétrica. Visando amenizar estes problemas, algumas famílias uniram-se para a construção de poços artesianos, entretanto esta iniciativa ficou restrita àquelas famílias que tinham acesso a energia elétrica. Pensamos que na medida em que os recursos forem liberados, as condições de moradia tendem a melhorar, juntamente com os projetos e investimentos federais de instalação de rede elétrica e de saneamento básico.

A partir desta situação na qual se encontra o assentamento, podemos inferir que uma das principais premissas para a concretização do assentamento, da reforma agrária, na área de estudo são os investimentos federais e estaduais em infra-estruturas básicas. Porém, as verbas aprovadas para este assentamento até o momento não foram liberadas, dificultando o bom desenvolvimento do projeto. Cabe lembrar que as dimensões do assentamento dificultam a organização dos assentados, tanto em relação ao MST, quanto em relação à produção. Esta situação é maximizada por precárias condições apresentadas pelas vias internas do assentamento.

Uma das formas de amenizar estas dificuldades foi à construção das agrovilas, entretanto, apenas isso não é suficiente, nesse sentido, existe uma tentativa de reorganização espacial, a partir da divisão do assentamento em cinco assentamentos menores, obedecendo a atual organização dos setores. 
Existem também a necessidade de adaptação, tanto de caráter cultural como ambientais, visto que, a região de origem da maioria dos assentados, o noroeste do Rio Grande do Sul, caracteriza-se por ser uma área de colonização de várias etnias, sobretudo de italianos e alemães e apresenta determinadas características ambientais onde desenvolveramse mais facilmente os cultivos de milho, trigo e soja. No assentamento essas características ambientais são bastante diferentes, obrigando os assentados a adotarem novas práticas de cultivo e de organização sócio-espacial. A forma encontrada para superar as dificuldades de adaptação está bastante calcada na coletividade das atividades, tanto da produção quanto da busca das infra-estruturas necessárias.

A coletividade, que em princípio nos parece ser um bom caminho para a superação das dificuldades de adaptação e de infra-estruturas, esbarra em divergências religiosas que ficaram guardadas durante o período de acampamento. Onde as práticas ecumênicas eram promovidas e a coletividade tratada como caminho para a conquista da terra. De forma que aqueles assentados que permaneceram por mais tempo no acampamento apresentam maior tendência à coletividade, existindo, portanto, uma relação entre o tempo de acampamento e a disposição às práticas coletivas. No momento posterior ao acampamento, já assentadas, as famílias tendem a restaurar seus credos, isso fica bastante claro no fato da existência de templos de diversas religiões dentro do assentamento. Historicamente a partir de suas pastorais as Igrejas Católica e Luterana, possuem uma ligação ao MST, facilitando a organização do movimento e a coletividade nos setores onde estas predominam ou atuam mais fortemente.

No que se relaciona ao setor econômico é importante ressaltar que algumas das questões tornam a coletividade da produção a saída mais viável em virtude dos grandes investimentos necessários à mecanização, que em virtude dos aspectos levantados, ambientais e econômicos, está posta para este assentamento.

As atividades fora do assentamento ou mesmo dentro deste que não são ligadas à produção agrícola; em atividades como eletricistas, cabeleireiros, funcionário de indústria, etc, serviram num primeiro momento para superar as dificuldades financeiras enfrentadas em virtude do atraso de investimentos governamentais. Entretanto atualmente essa pluriatividade atrapalha a identificação do indivíduo com o grupo de assentados fragilizando as relações de produção coletiva. Tais aspectos são difíceis de serem evitados em virtude de que a localização dentro da Região Metropolitana de Porto Alegre oferece muitas oportunidades e podem se tornar um enclave à continuidade do assentamento dentro do ideal do campesinato. 
Existem grandes diferenças quando a forma de produzir, coletivas, individuais ou cooperativadas. Também, ocorrem diferenças em relação a sua comercialização, tal disparidade parece encontrar no diálogo o resultado para sua .

Os problemas de ordem infraestrutural necessitam serem sanados para o melhor andamento e diversificação da produção é o caso das quantidade limitada de água, as más condições das vias, a conclusão dos projetos de eletrificação e a regulamentação do fornecimento de água. $\mathrm{Na}$ parte mais técnica existe uma disparidade bastante grande em relação ao domínio de técnicas de cultivo do arroz, entende-se que as reuniões que vem sendo realizadas e um apoio efetivo por parte governamental na oferta de assistência técnica deve minimizar esse problema a médio prazo.

Noutro aspecto, o Município de Viamão já possui um histórico de ocupação dos áreas de várzeas desde a década dos anos setenta para o cultivo de arroz. Portanto, a partir desta época, profundas alterações foram estabelecidas sobre este meio, como drenagens de solos, terraplanagens, canalizações, etc. A própria construção da barragem existente dentro do assentamento é um exemplo disto. Ainda assim, mesmo com tantas alterações, existem ainda áreas em considerável condição de preservação, tanto da flora como da fauna. Esta situação nos remete à ausência de um Plano de Manejo da APA, ou do assentamento como um todo. Pois infraestruturas instaladas como a barragem já estão "harmonizadas" ao meio, e seu uso e manuseio pode ter grandes impactos sobre essa estabilidade. São problemas que têm como resultados a degradação deste ambiente, o incentivo ao desrespeito de leis ambientais, pouco conhecidas, em fim, é uma grande falta de um governo que tanto cobra a preservação.

Este fatores associados a falta de conhecimento deste novo ambiente pelos assentados e suas idéias bastante fragmentadas sobre preservação, a necessidade de democratização dos conhecimentos em agroecologia apontam para a necessidade de uma atividade educativa de caráter ambiental, para a construção de um projeto de educação ambiental baseado nas necessidades desta comunidade.

Partindo do diagnóstico sócio-cultural e de percepção ambiental que realizamos no Assentamento Filhos de Sepé, chegamos à conclusão de que poderíamos contribuir junto ao mesmo com um trabalho de Educação Ambiental, levando a uma comunidade de assentados aquilo que é obrigação do Estado oferecer e direito de todos receber: educação gratuita, de qualidade, com ideais libertários, socialmente e ecologicamente responsável. Nesse sentido, o objetivo fundamental de nosso trabalho foi ampliar os conceitos de ambiente, natureza, ecologia e cidadania das crianças, jovens e adultos do Assentamento Filhos de Sepé, com 
especial atenção à superação da visão antropocêntrica e individualista predominante na sociedade ocidental. Tal ampliação exige uma mudança de atitude e postura dos educadores e, conseqüentemente, também dos educandos. Quanto aos objetivos específicos, foram eles:

- Discutir com os assentados a questão ambiental e suas correlações com as questões econômicas e sociais;

- Discutir a inserção da Área de Proteção Ambiental e do Refúgio da Vida Silvestre junto ao Assentamento;

- Compreender a importância do Banhado Grande para o Assentamento e para região metropolitana;

- Desenvolver o entendimento das questões ambientais e sua estreita relação com a saúde;

- Discutir a organização local como forma de resistência social e como base para atividades ambientalmente viáveis;

- Reconhecer as especificidades locais e suas relações com as diferenças regionais. 
Figura 1: Localização do Assentamento

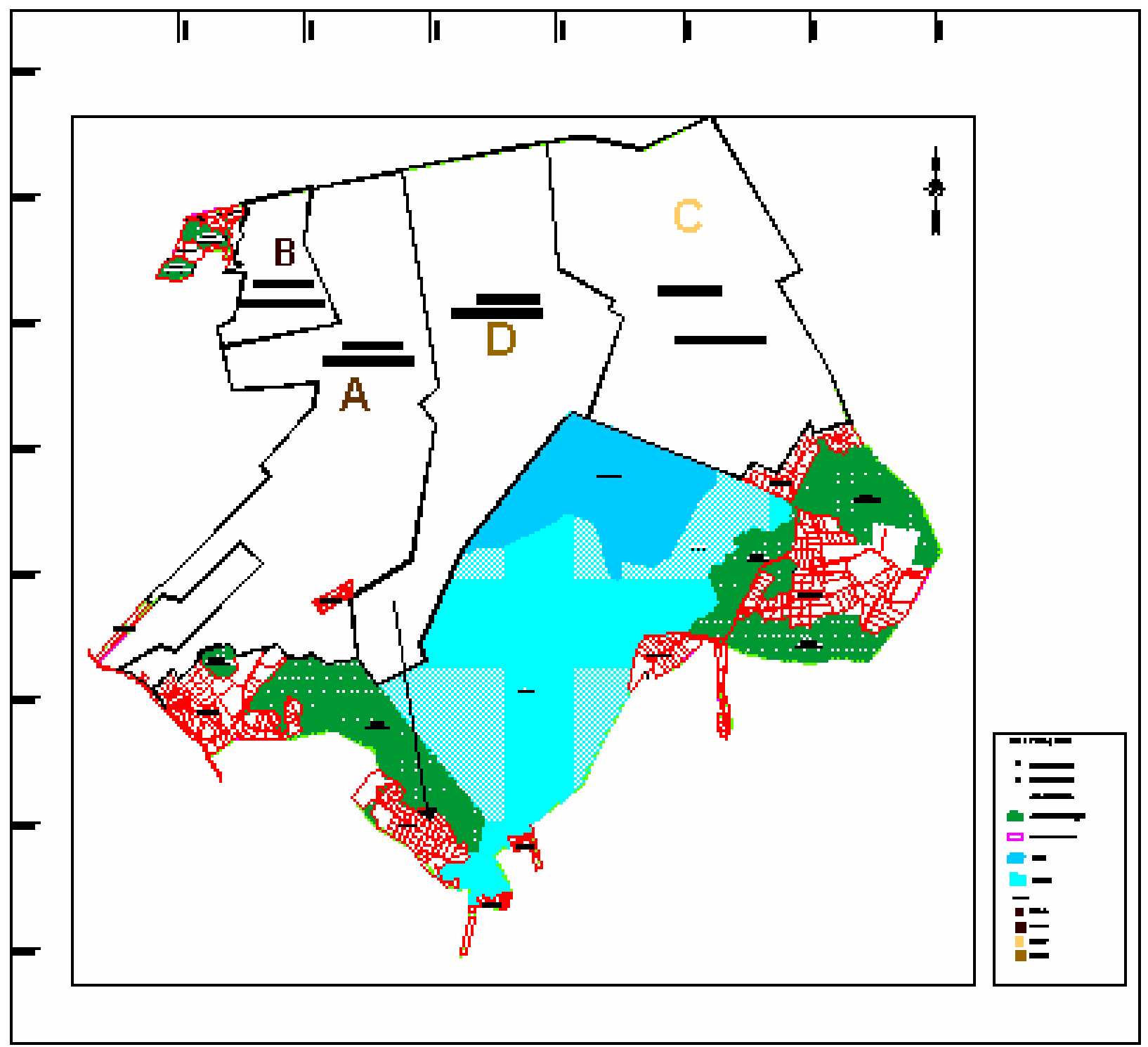

Fonte: Mapa-base - Gabinete de Reforma Agrária, 2000; Mapa temático - Jorge A A Lemos, 2001. Mapa ilustrativo não obedecendo referência de escala. 
Figura 2: Uso do solo na área do assentamento

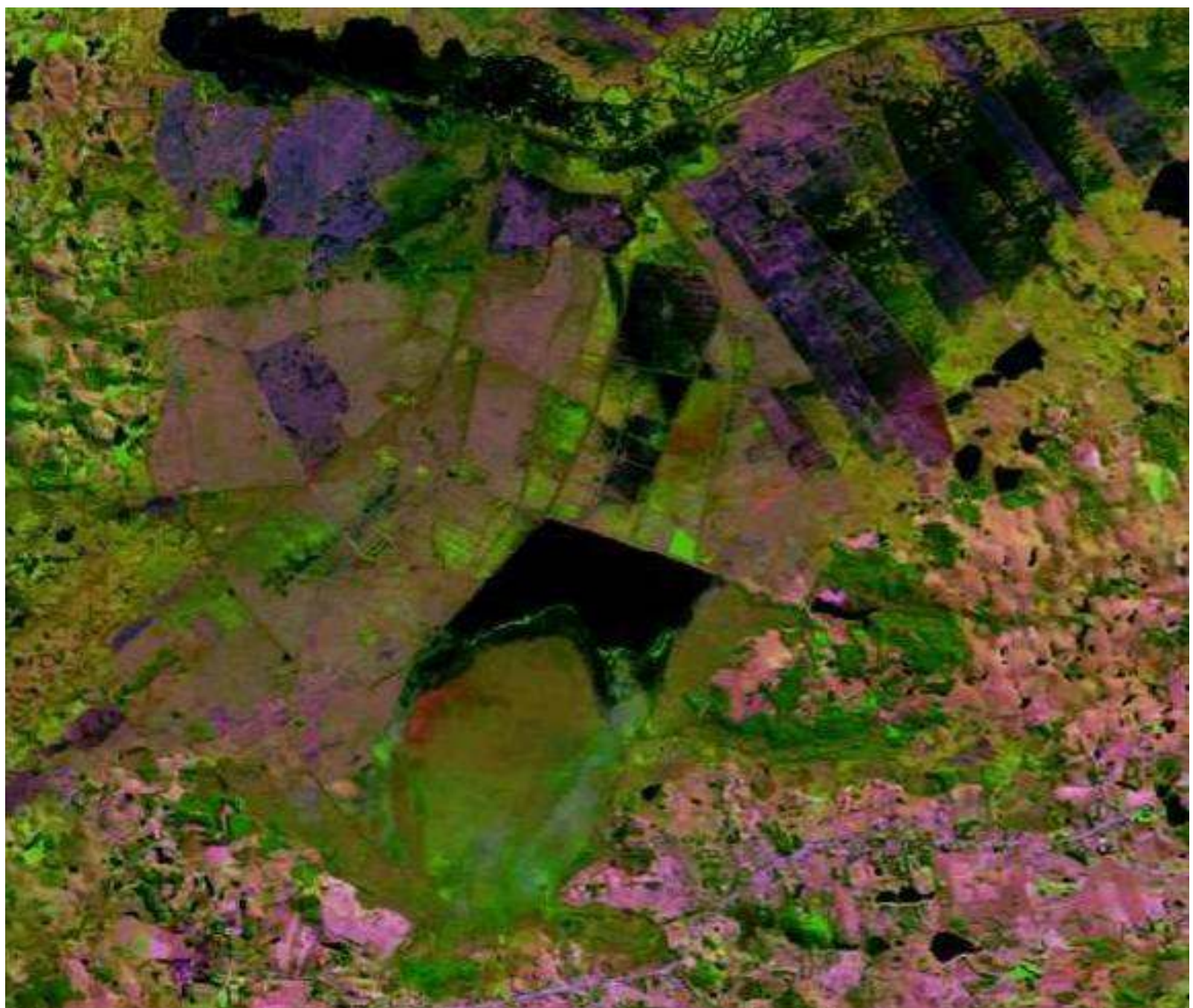

Fonte: EMATER, 2003 - Imagem de Satélite (Falsa Cor, Folha SH-22-Z-A-I-L, Imagem ilustrativa não obedecendo referência de escala)

\section{Procedimentos Metodológicos}

Partindo do Diagnóstico Sócio-cultural e de Percepção Ambiental e apoiado na bibliografia genérica em torno da temática ambiental, levantamos oito temas geradores de relevante importância ao Assentamento e que permitem a reflexão sobre cidadania. Vale acrescentar que esses temas tiveram caráter propositivo, possibilitando modificações segundo sugestões dos assentados. A proposta de trabalhar com temas geradores surgiu da necessidade de “estimular 'situações-limite' que desestruturem preconceitos e criem condições para que o aluno construa uma visão de mundo mais dialética e menos dogmática" (Kaercher, 1993, p.56). Neste caso, criar condições para os assentados construírem sua visão de mundo. Cabe ainda mencionar Freire apud Kaercher, onde "procurar o tema gerador é procurar o 
pensamento do homem sobre a realidade e a sua ação sobre esta realidade que está em sua práxis" (1993, p.56).. São os temas:

1. O Assentamento e seu entorno

2. Paisagem

3. Meu lugar, meu espaço

4. Ambiente e saúde

5. O Banhado Grande e a água

6. Lixo

7. Sociedade e participação

8. Agroecologia

Ao mesmo tempo, estes temas foram estruturados a partir de três dimensões principais, a saber:

Histórico-Cultural: Esta dimensão abrange a história de vida reconstituída de cada assentado, bem como a história do Movimento dos Trabalhadores Rurais Sem Terra e sua trajetória. Por se tratar de um assentamento composto por famílias provenientes de diversas regiões do estado, a diversidade cultural insere-se num dos elementos fundamentais a ser trabalhado.

Sócio-Econômica: Do mesmo modo, deve-se levar em consideração a necessidade da discussão e democratização das relações sociais vigentes em um assentamento, como a de coletividade entre os assentados, assim como as relações do assentamento com as demais instituições, como o próprio Estado.

Biogeográfica: Esta dimensão está centrada na discussão do conceito de natureza, posto que, para que se modifiquem as relações sociais e relações de poder, é necessário que antes se modifique a maneira como o homem percebe o que é natureza. Estas dimensões tem por finalidade buscar uma maior aproximação da realidade dos assentados, através das suas vivências e também de suas concepções referentes ao espaço geográfico, sendo elas apoiadas no Diagnostico Sócio-cultural e de Percepção Ambiental realizado neste assentamento no período de 2000 a 2003.

Por fim, cada tema gerador resultou em uma oficina, que teve a duração de um turno ${ }^{4}$. Os materiais utilizados variaram de acordo com cada tema, priorizando as atividades de caráter lúdico, pois segundo Brougère

(...) cultura lúdica não é só composta de estruturas de brincadeiras, de manipulações em potencial que podem ser atualizadas. Ela também é

\footnotetext{
${ }^{4}$ Aproximadamente três horas
} 
simbólica, suporte de representações. A brincadeira é, igualmente, imaginação, relatos, histórias, [onde] ... essa cultura lúdica irá constituir uma bagagem cultural para a criança e se incorporar de modo dinâmico à cultura, à capacidade de criação do futuro adulto .(1997. p. 51 e 52).

\section{Fluxograma Metodologia Utilizada ${ }^{5}$}

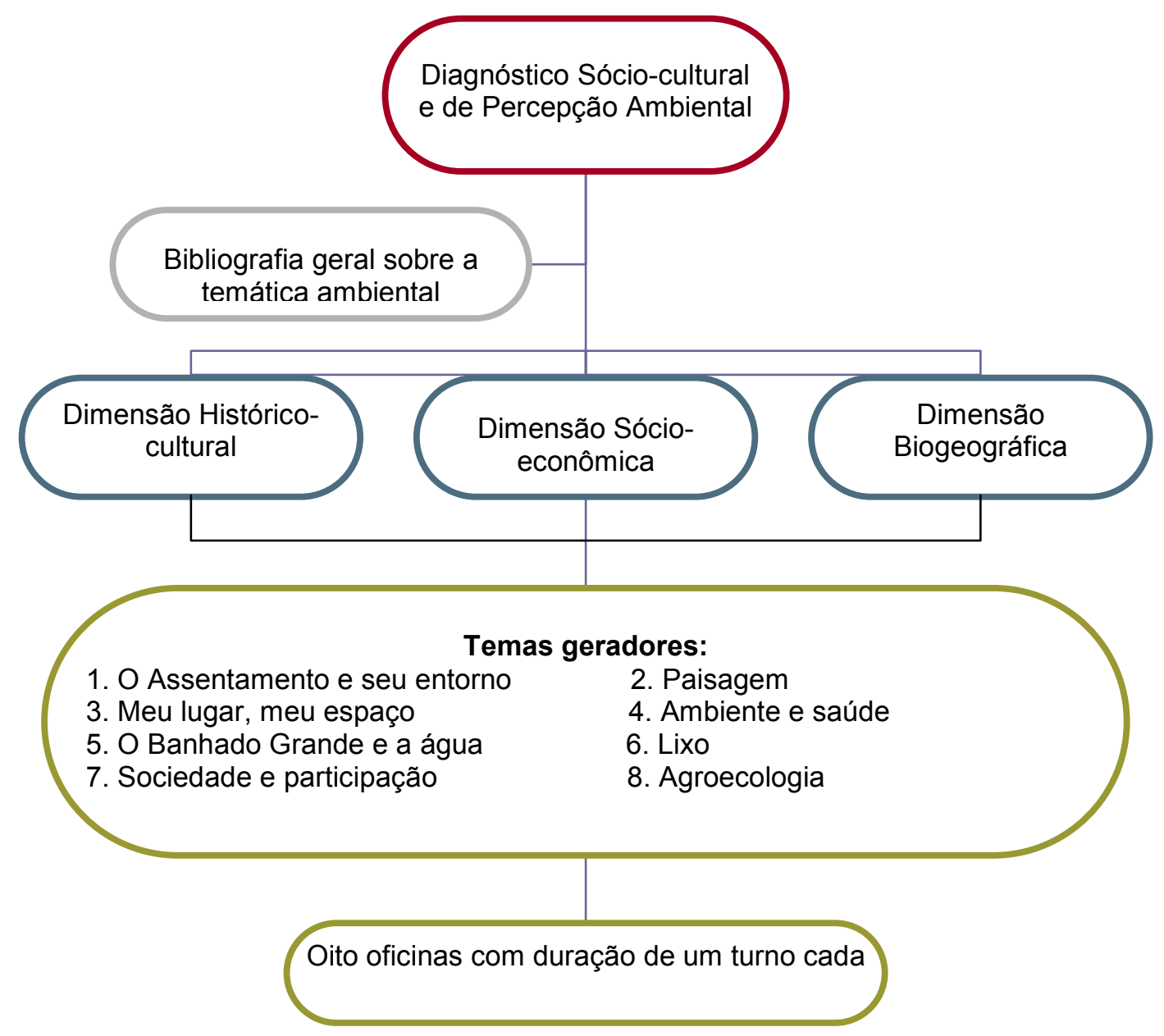

\section{Educação Ambiental Na Prática}

O projeto de Educação Ambiental foi aplicado entre os dias 26 e 30 de janeiro do ano de 2004 no Assentamento Filhos de Sepé, município de Viamão/RS. Participaram da experiência em Educação Ambiental os nove autores bolsistas do grupo PET Geografia da

\footnotetext{
${ }^{5}$ Fluxograma demonstrando a estrutura metodológica
} 
UFRGS $^{6}$, juntamente com quatro bolsistas do grupo PET Psicologia da UFRGS $^{7}$ e um graduando em Geografia da Universidade “du Maine” (Le Mans/França) ${ }^{8}$.

Na primeira etapa, os temas foram desenvolvidos através de uma divisão realizada por monitorias dos bolsistas envolvidos. Nesse sentido, foram formados dois grupos, o primeiro ficou responsável pelas crianças e o segundo pelos adolescentes, sendo, que cada integrante do grupo desenvolveu anteriormente pesquisas sobre cada uma das dimensões básicas do trabalho 9 .

Os quatro bolsistas do grupo PET Psicologia tiveram como função avaliar e direcionar a forma de trabalho ${ }^{10}$ com os assentados, procurando dessa forma obter um melhor resultado possível, além de auxiliar na relação de trabalho coletivo do grupo de monitores.

Quanto ao desenvolvimento dos temas geradores, no primeiro dia foi trabalhado o tema 'O Assentamento e seu Entorno', que teve como proposta mostrar aos assentados a sua localização, apresentando-lhes um mapa de localização para que pudessem se situar, além de mostrar as cidades do entorno do assentamento, explicando que este encontra-se situado numa região metropolitana. Relacionado ainda a esse tema, foi-lhes perguntado sobre suas cidades natais. Nesse primeiro dia apenas crianças participaram do projeto, necessitando adaptações à metodologia, para que fossem atingidos os objetivos pré-estabelecidos. A solução encontrada foi procurar trabalhar o tema dando mais ênfase às atividades lúdicas, para aumentar o seu interesse pela atividade.

Os temas 'Paisagem' e 'Meu Lugar, Meu Espaço' foram trabalhados no segundo dia, sendo que nesse houve a participação de adolescentes. Por esse motivo, os participantes foram divididos em dois grupos; um de crianças e um de adolescentes. É importante ressaltar que algumas das atividades do dia anterior tiveram que ser retomadas, pois havia um razoável número de novos participantes.

Com as crianças, continuou-se trabalhando os objetivos dos temas com atividades lúdicas, tais como jogos e pinturas.

Nesse dia, como um dos temas abordados referia-se a paisagem, tanto crianças como adolescentes foram levados a uma das partes mais altas do assentamento, onde estes puderam avistar a maior parte do assentamento; locais como a barragem e a plantação de arroz. Essa

\footnotetext{
${ }^{6}$ Ana Stumpf Mitchell, Fábio Guadagnin, Felipe Silveira de Souza, Fernando Mousquer, Gustavo Luis Ferri Furini, Judeci da Silva, Márcia Milene Müller, Neudy Alexandro Demichei, Tiago Oliveira Nicoloso.

${ }^{7}$ Aline Mocelim, Ana Paula Tíbulo, Janaína Zanchin, Raquel Valiente Frosi

${ }^{8}$ Graduando de Intercâmbio Guillaume Leturcq

${ }^{9}$ Dimensão Histórico-cultural, Sócio-econômica e Biogeográfica.

${ }^{10}$ tendo como embasamento teórico as discussões feitas sobre dinâmica de grupo
} 
idéia surgiu após o trabalho com os adolescentes, onde constatou-se que os mapas por eles desenhados estavam desconexos, pois alguns colocaram a área de cultivo de arroz próxima a barragem, enquanto outros a colocaram em locais distantes a barragem.

No terceiro dia, pela parte da manhã o tema abordado foi 'O Banhado Grande e a Água', sendo que a sistemática de trabalho ocorreu como nos dias anteriores, No grupo de adolescentes, o trabalho voltou-se para a importância que o Banhado e a água têm para o assentamento. Em relação às crianças, a dinâmica deste deu-se com a visitação de um dos córregos que desembocam na barragem, mostrando e explicando a estas a importância que o arroio tem para com a comunidade, e a necessidade dos mesmos de preservá-lo, explicandolhes que é a partir deste córrego que um grande número de famílias têm seu lazer e, principalmente, pelo fato desse curso d'água abastecer a barragem que banha o principal produto do assentamento, o arroz. Após esta atividade, realizou-se atividades lúdicas envolvendo o assunto trabalhado, procurando desta forma obter um resultado mais significativo, junto as crianças.

Nesse mesmo dia, à tarde aconteceu uma atividade diferenciada, onde houve a participação do médico Rafael de Medeiros Mitchell, discutindo com a comunidade o tema 'Ambiente e Saúde'. A atividade foi bem diferente das já trabalhadas, pois houve a participação de dezenas de mães do assentamento. Para se ter um bom resultado com o grupo de mães, um grupo de bolsistas trabalhou com as crianças, realizando atividades lúdicas, voltadas a recapitulação dos temas já trabalhados, além do tema 'Ambiente e Saúde'. Nesta atividade foi dado destaque a importância da água, correlacionando sua utilização adequada com a saúde da comunidade.

No quarto dia, o tema abordado pela parte da manhã estava relacionado à problemática 'Lixo'. Para a aplicação deste tema, foi exibido o curta-metragem Ilha das Flores de Jorge Furtado. Tal curta-metragem mostra a problemática causada pelos depósitos de lixo em uma vila, neste caso, a Vila Ilha das Flores (Ilha dos Marinheiros - Porto Alegre), e todas as relações da produção do lixo com o consumo de produtos, sejam eles primários ou secundários. Após o vídeo, foi feito um debate com as crianças, fazendo com que elas discutissem o que haviam visto e aprendido em relação ao filme, possibilitando relacionar ou não com o local onde residem. Após esta fala, com o intuito de melhor fixar o assunto, dividimos as crianças em dois grupos - um de meninas e outro de meninos - dando-lhes a atividade de coletar resíduos de lixo nos arredores, dividindo este em seco e orgânico. Ao término desta tarefa, trabalhou-se com uma atividade lúdica que propiciasse a agregação do tema lixo. Em virtude disto trabalhamos com as crianças, fazendo uma roda, e com uma bola 
que passava de mão em mão, onde um dos bolsistas, que ficava afastado da roda, dava um sinal e quem estivesse com a bola deveria mencionar um tipo de lixo seco ou orgânico.

À tarde, foi trabalhado o tema 'Sociedade e Participação', onde, como nos dias anteriores, iniciou-se com uma recapitulação dos temas já abordados. Após essas atividades, se iniciou as atividades do tema supracitado. Este tema teve como finalidade perpassar aos assentados a importância do trabalho comunitário. É interessante ressaltar que este tema tem uma importância fundamental junto aos assentados, conforme diagnóstico anteriormente realizado11. A partir disto, a atividade foi trabalhada da seguinte forma:

Primeiro objetivamos um diálogo com as crianças, onde procuramos discutir a forma como as famílias do assentamento trabalham, mostrando a importância do trabalho coletivo.

Após ter-se realizado o primeiro passo, partiu-se para a aplicabilidade da idéia de trabalhar em coletividade, com a realização de uma atividade recreativa, onde as crianças teriam que se organizar, para juntas adquirir as três propostas de atividade recreativa. Cada criança obtinha três pedras que seriam para "comprarem" a brincadeira. As brincadeiras eram: Proposta 1: Jogar futebol (30 pedras)

Proposta 2: Música da Serpente (30 pedras)

Proposta 3: Música do Tchu Tchuá (20 pedras)

No final da atividade, elas apenas conseguiram adquirir duas propostas, mesmo tendo mais de 80 pedras com eles. Com esta situação, trabalhou-se o motivo delas não terem adquirido as três propostas; mostrando que não havia se realizado um eficiente trabalho coletivo. Após esta fala com as crianças, realizou-se as atividades lúdicas escolhidas ou compradas por elas, que foram a Música do Tchu Tchuá e a Música da Serpente.

Após o término das atividades de recreação, o trabalho final do dia foi com papel pardo e canetas, onde foi pedido as crianças que desenhassem as suas casas e suas famílias.

No último dia o tema trabalhado no turno da manhã foi 'Agroecologia' e, à tarde voltada a uma confraternização com as crianças, tendo a participação de alguns alunos do pósgraduação do Programa de Pós-Gradução em Geografia da Universidade Federal do Rio Grande do Sul (PPGGea UFRGS).

Em relação ao desenvolvimento do tema 'Agroecologia', este deu-se de uma forma bem diferenciada quanto a maneira de aplicação. Esta atividade foi trabalhada em forma de teatro, pois possibilitava a abordagem dos temas já trabalhados, além do próprio tema.

A dinâmica de desenvolvimento do teatro aconteceu da seguinte forma:

\footnotetext{
${ }^{11}$ Diagnóstico Sócio-cultural e de Percepção Ambiental realizado pelo grupo PET Geografia no ano de 2000 a 2003 junto ao Assentamento Filhos de Sepé.
} 
Com o intuito de explicar o tema Agroecologia e abordar as diferenças entre os alimentos agroecológicos e os convencionais ${ }^{12}$, o teatro baseou-se em uma feira, onde haviam dois feirantes, sendo um vendedor de alimentos agroecológicos, enquanto o segundo, vendedor de alimentos produzidos de formas convencionais.

Incluso a isto, havia duas senhoras que estavam fazendo compras, onde uma delas não conhecia os alimentos agroecológicos. Primeiramente, uma das senhoras se interessou pelo alimento agroecológico, fazendo perguntas sobre o mesmo, como era produzido. O feirante prontamente respondeu explicando que o mesmo não havia agrotóxicos, produzido em escala familiar, além de não agredir o meio ambiente. Porém, essa forma de cultivo acabava resultando num preço maior ao consumidor em relação ao alimento produzido de forma “convencional". Está senhora acabava ficando em dúvida sobre comprar um produto mais caro, porém com inúmeras vantagens para a sua saúde, além de estar preservando importantes recursos naturais, ou comprar o produto tradicional.

Após, chegava a segunda senhora, que encontrava sua amiga com dúvidas sobre qual seria o melhor alimento a ser comprado. Por a segunda senhora ter conhecimento sobre o assunto, estas conversam sobre o mesmo, onde esta aconselha sua amiga a comprar o produto agroecológico.

Neste primeiro momento apenas os bolsistas participaram do teatro, ao tempo em que as crianças assistiam.

Com o término do teatro, representado pelo grupo de bolsistas; foi a vez das crianças representarem os feirantes, procurando vender os seus produtos para os freqüentadores da feira, representados pelo bolsistas.

O tema agroecologia foi abordado por ser chamado atualmente de agricultura sustentável $^{13}$, é sabido que o Movimento do Trabalhadores Sem Terra tem uma ideologia voltada à pequena produção. Sobre a discussão filosófica do termo agroecologia, busca-se apoio em Altieri, onde, "a agroecologia fornece os princípios ecológicos básicos para o estudo e tratamento de ecossistemas tanto produtivos quanto preservadores dos recursos naturais, e que sejam culturalmente sensíveis, socialmente justos e economicamente viáveis" (1998, p. 17).

\section{Considerações Finais}

\footnotetext{
${ }^{12}$ Caracteriza-se aqui alimentos convencionais, aqueles produzidos em larga escala, onde segundo Altieri, “as estratégias de desenvolvimento convencionais revelaram-se fundamentalmente limitadas em sua capacidade de promover um desenvolvimento equânime e sustentável".

${ }^{13}$ Baseado na concepção de Miguel Altieri.
} 
Na prática de educação ambiental, observou-se que o trabalho com os adolescentes, embora dinâmico, foi prejudicado pela desistência dos mesmos. Quanto às crianças, buscouse trabalhar os temas através de atividades lúdicas, tais como jogos e pinturas, porém, o entendimento destas ficou restrito ao lúdico. A necessidade de atividades lúdicas que permeassem nossa metodologia, surgida a partir da realidade e das dificuldades encontradas, tornou esta experiência significativa, uma vez que foi o agente facilitador do trabalho junto às crianças assentadas. É importante ressaltar que o objetivo principal do projeto, ou seja, a compreensão da realidade a partir das várias esferas do conhecimento/saber e o despertar da cidadania, não foi alcançado em sua plenitude. Entretanto, entende-se que novos questionamentos se fizeram presentes dando uma nova configuração aos objetivos inicialmente propostos e que estarão abrindo espaços para a continuidade deste projeto independente da forma e do objetivo inicial.

\section{Referências Bibliográficas}

ALTIERI, Miguel. Agroecologia: a dinâmica produtiva da agricultura sustentável. Porto Alegre: Ed. Universidade/UFRGS, 1998;

BROUGÈRE, Gilles. Brinquedo e cultura. São Paulo: Ed. Cortez, 1997.

CALDEIRON, Sueli Sirena (coordenadora). Recursos naturais e meio ambiente: uma visão do Brasil. Rio de Janeiro: IBGE, 1993.

DEMICHEI, N.; FURINI, G.; GUADAGNIN, F.; MEDEIROS, R.M.V.; MOUSQUER, F.; MÜLlER, M.; NICOLOSO, T.; SILVA, J. DA; SILVEIRA DE SOUZA, F.; MITCHELL, A.S. A percepção ambiental no Assentamento Filhos de Sepé, Viamão/RS, frente às questões sócio culturais. In: XIII Salão de Iniciação Científica da Universidade Federal do Rio Grande do Sul. Porto Alegre: UFRGS, 2003.

. Educação ambiental no Assentamento Filhos de Sepé, Viamão/RS. In: XIII Salão de Iniciação Científica da Universidade Federal do Rio Grande do Sul. Porto Alegre: UFRGS, 2003.

FOSCHIERA, Elisabeth Maria. Educação ambiental e desenvolvimento: projeto PróGuaíba na escola. Passo Fundo: UPF, 2002.

GONÇALVES, Carlos Walter. Os (des)caminhos do meio ambiente. São Paulo: Contexto, 1989.

KAERCHER, Nestor André. Desafios e utopias no ensino de geografia. Santa Cruz do Sul: EDUNISC, 1997. 
MESQUITA, Olindina Vianna; SILVA, Solange Tietzmann (coordenadoras). Geografia e questão ambiental. Rio de Janeiro: IBGE, 1993.

NORONHA, Luiz C. (org.). Baía de todas as águas: preservação e gerenciamento ambiental na Bacia Hidrográfica do Guaíba. Porto Alegre: Secretaria Executiva do PróGuaíba, 1998.

REVISTA CIÊNCIA E AMBIENTE. Universidade Federal de Santa Maria. Gestão das águas. V. 1, n.1. Santa Maria: UFSM, jul. 1990.

REVISTA DA CASA DA GEOGRAFIA DE SOBRAL. Geociências/Universidade Estadual Vale Acaraú. Sobral: cenários e paisagens. V.I, n. I. Sobral - CE: UVA, jan./dez. 1999.

RIO GRANDE DO SUL. Secretaria da Educação. Departamento Pedagógico. Divisão de Ensino Fundamental. Experiências em educação ambiental: pressupostos orientadores. Volume 1. Porto Alegre: Governo do Estado do Rio Grande do Sul / Pró-Guaíba / Projeto de Educação Ambiental, 1998.

VIANNA, Aurélio; MENEZES, Lais; IÓRIO, Maria Cecília; RIBEIRO, Vera Masagão (orgs.). Educação ambiental: uma abordagem pedagógica dos temas da atualidade. São Paulo: CEDI; Erexim, RS: CRAB, 1992. 